\title{
Co-gasification of Corn and Coconut Residues in Downdraft Gasifier
}

\author{
Norazilah Tamili1, ${ }^{1,}$, Lee Kean Chuan ${ }^{1}$, Shaharin A. Sulaiman², Mohamad Nazmi Z. Moni², \\ Muddasser Inayat ${ }^{2}$, and Michael Yin Kai $\mathrm{Lo}^{2}$ \\ ${ }^{1}$ Department of Fundamental and Applied Science, Universiti Teknologi PETRONAS, 32610 Seri \\ Iskandar, Perak, Malaysia \\ ${ }^{2}$ Department of Mechanical Engineering, Universiti Teknologi PETRONAS, 32610 Seri Iskandar, \\ Perak, Malaysia
}

\begin{abstract}
Reliance on a single biomass to generate electrical power can cause disruption due to the inconsistencies in the supply of biomass feedstock. Co-gasification of different biomass can mitigate the problem of inconsistence biomass supply. The aim of this study to investigate thermochemical properties of corn residues (CR) and coconut shells (CS) and syngas performance produced from co-gasification of CR and CS. Biomass materials were characterized in order to understand their physical properties in relation to thermochemical conversion. Co-gasification of CR and CS was carried out in externally heated downdraft gasifier at CR:CS ratio of 50:50, 40:60 and 20: 80. CO composition obtained from blended feedstock is higher as compared to the without blended feedstock. The $\mathrm{CO}_{2}$ and $\mathrm{CH}_{4}$ concentration were increased as CS proportion increased in blend. Biomass with higher moisture content plays important role in the $\mathrm{H}_{2}$ production due to the supercritical water gasification. The blending ratio of CR and CS at 20:80 had a positive synergetic effect as evident by increase in the gas composition for $\mathrm{CO}, \mathrm{CH}_{4}$ and $\mathrm{H}_{2}$. It is concluded that cogasification results of $\mathrm{CR}$ and $\mathrm{CS}$ is practical and can be considered to complement each other.
\end{abstract}

\section{Introduction}

Biomass considered as a renewable source of energy due to its reproducible nature of supply. Biomass is also seen as an interesting energy source since it is efficient and costeffective which can contribute to sustainable development [1]. Biomass energy conversion can be carried out by using thermochemical processes such as combustion, gasification, torrefaction, and pyrolysis. These processes can break down the harder structure of biomass that is held in lignin and convert it into heat, fuel gas and bio-oil. Gasification is the most considered and suitable process since it releases minimum amount of greenhouse gases as compared to combustion process $[2,3]$. Combustion is an exothermic reaction between oxygen and hydrocarbon in biomass. Combustion is an alternative and the quickest thermochemical process to produce heat for energy generation but it has many setbacks

\footnotetext{
*Corresponding author: norazilahtamili@gmail.com
} 
compared to gasification. One of the suitable ways to substitute combustion is through gasification. Gasification is a thermochemical process in which converts biomass into producer gas that consists of hydrogen, methane, carbon monoxide, and carbon dioxide. Biomass feedstock is the cheapest option for gasification in order to generate electrical power in rural areas. However, the limitations of biomass supply due to various reasons such as heavy flood, rain, drought, and seasonal change can affect the continuity of biomass feedstock supply. Therefore, reliance on a single biomass can cause interruption for the continuous gasification operation for electricity generation [4-8]. Hence, co-gasification of different biomass feedstock can help mitigate problems related to inconsistencies in feedstock supply. However, study on co-gasification of different biomass is scarce. Cogasification is a type of gasification process in which two or more than two feedstock gasify together in the same gasifier. There is a limited study available on co-gasification of different biomass materials for generating electricity. The objective of the present work is to study the characterization of corn residues and coconut shells and furthermore study the performance of the syngas produced at various operating conditions. The output of this study would be vital information on the technical feasibility of co-gasification of different biomass for consideration by the industries.

\section{Methodology \& experimental setup}

In this study, two biomass materials corn residues (CR) and coconut shells (CS) were used. Corn stovers were collected from nearby area Bota, Perak and coconut shells were collected from the wet market. The feedstocks were prepared prior to gasification the preparation included drying and granulating. The feedstocks were dried for 24 hours using an electric oven to remove the biomass moisture. After drying, the feedstocks were granulated using the granulator into small particles. Ultimate and proximate analyses of samples were carried out as per American Society for Testing and Materials (ASTM) standard. Thermogravimetric (TGA) analyzer was used to determine the proximate analysis. The sample was heated up to $850^{\circ} \mathrm{C}$ at $10 \mathrm{~K}$ heating rate. The result from the thermogravimetric curve, the moisture content, volatile matter, fixed carbon, and ash was determined. The ultimate analysis is important for biomass characterization to determine carbon, hydrogen, nitrogen, and sulphur contents of samples. It is useful to know the suitability of the feedstock for energy production. Series II CHNS/O analyzer was used for this analysis. Higher heating value (HHV) was determined using the bomb calorimeter. This HHV plays an important role in the design and control of the power plant [9].

Biomass samples co-gasified in an externally heated downdraft gasifier. Fig. 1 shows the schematic of the gasifier and its associated equipment's used for biomass gasification. A premeasure biomass blend was feed to gasifier from its top once it achieves the desired temperature. The maximum temperature of the current experiment was $900^{\circ} \mathrm{C}$. A control and measure quality of air was supplied by a rotameter. The products of biomass gasification were syngas, liquid, and solid. For the solid part, ash, charcoal, and minerals were obtained at the end of the gasification process, as for the liquid tar and condensates were during the process. The syngas consists of $\mathrm{H}_{2}, \mathrm{CO}, \mathrm{CH}_{4}$, and $\mathrm{CO}_{2}$.

\section{Results and discussion}

\subsection{Proximate analysis}

Proximate analysis for CR and CS were identified to determine the value of volatile matter, moisture content, fixed carbon, and ash. Table 1 shows the results of proximate analysis obtained from biomass fuels used in the present work. CR contains higher moisture content compared to CS by $14.04 \%$ followed by CS $11.34 \%$. The moisture content of CS is 
higher due to the differences in the collection and storage procedures and different techniques used for determination of moisture content. From the study of Yao et al [10], moisture value of below $10 \%$ for pre-dried biomass and as high as 50\% in fresh crops while Permchart and Kouprianov [11], reported that moisture level of lower than $50 \%$ would be effectively used in combustion. The volatile matter of CR has a higher value of $82.87 \%$ as compared to CS. Biomass with higher volatile matter, indicate the possibility of obtaining an elevated amount of pyrolysis product. CS shows higher fixed carbon of $20 \%$ as compared to CR and this implies that CS has a potential for the gasification reaction since it can easily ignite the reaction. The ash content for both biomass is less than $2 \%$ however, CR shows higher percentage of ash compared to CS. The ash content in biomass is generally very small but plays a significant role in biomass utilization [12].

\subsection{Ultimate analysis}

Elemental composition for carbon, hydrogen, nitrogen and sulphur are determined by the ultimate analysis of CR and CS samples. Fig. 2a shows a histogram of elemental composition (CHNS) for CR and CS. CS has the highest carbon content of $47.28 \%$ while CR contains $40.15 \%$. The higher carbon content of biomass implies a good potential for biomass feedstock. Carbon reacts with oxygen during the combustion in an exothermic reaction to generate $\mathrm{CO}_{2}$ and $\mathrm{H}_{2} \mathrm{O}$. From this reactivity, carbon contributes to the fuel's higher heating value. The hydrogen content for each of the samples is near $6 \%$ and this is close to the result reported by Roberto et al, which was $5.6 \%$ to $7 \%$ [13]. The nitrogen contente for both samples are below $2 \%$. $\mathrm{N}$ is converted to gaseous $\mathrm{N}_{2}$ and the significant value of $\mathrm{N}$ was carried out by ashes [14]. The sulphur content of both samples has lower value of less than $1 \%$. The $\mathrm{SO}_{2}$ can be produced from $\mathrm{S}$ during gasification due to the presence of sulphur content, which is found in the both biomass fuels samples as a trace.

\subsection{Higher heating value}

Higher heating value (HHV) of biomass is the enthalpy of complete combustion including the condensation enthalpy of formed water. The HHV plays an important role in the design and control of the power plant $[9,15]$. The Fig. $2 b$ illustrates the heating values of biomass samples for grass $(\mathrm{G})$, corn residues (CR), woodchips (WC) [13], date palm fronds (DPF), [16] sugarcane bagasse (SCB) [17], wood (W) [17], coconut shells (CS), sawdust (SD), [13] and hazelnut shells (HS) [13]. CS has the highest value of HHV compared to the other two samples of biomass with the value of $17727 \mathrm{~J} / \mathrm{g}$. Therefore, CS is considered as a primary fuel due to the high value of HHV and this value depends on the biomass constituents and moisture content. The lignin part of the biomass plays a prominent role in the determination of higher heating value than other biomass constituents such as cellulose and hemicellulose. 

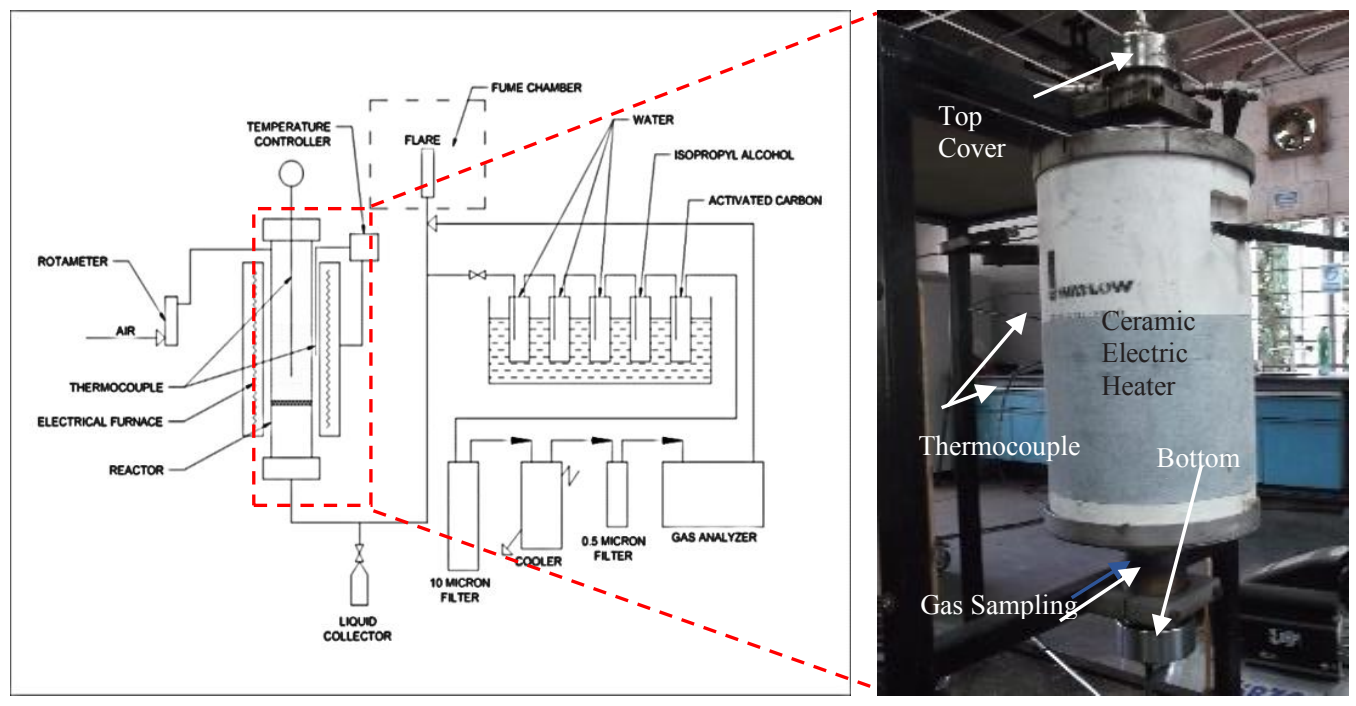

Fig. 1. Schematic gasification setup

Table 1. Proximate analysis of corn residues (CR) and coconut shell (CS)

\begin{tabular}{|c|c|c|c|c|}
\hline \multirow{2}{*}{ Biomass } & \multicolumn{4}{|c|}{ Proximate Analysis (\% weight) } \\
\cline { 2 - 5 } & Moisture Content & Volatile Matter & Fixed Carbon & Ash Content \\
\hline CR & 14.04 & 82.87 & 2.29 & 1.75 \\
\hline CS & 11.34 & 70.66 & 18.14 & 1.08 \\
\hline
\end{tabular}
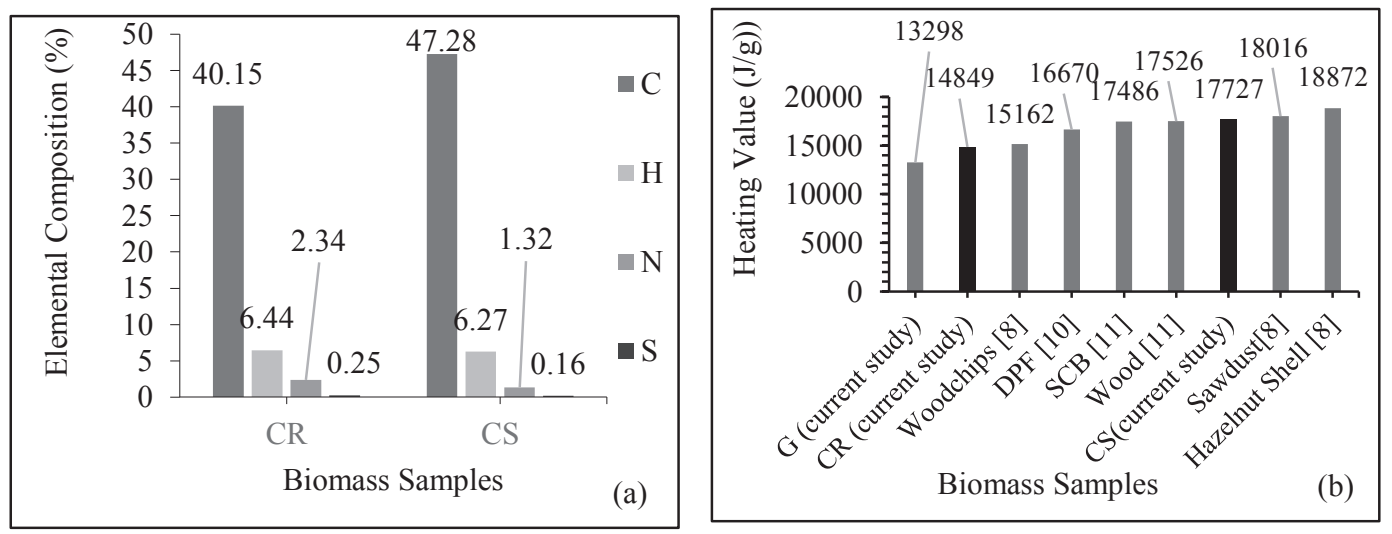

Fig. 2. (a) Ultimate analysis of CR and CS, (b) HHV of biomass samples (current study and previous study)

\subsection{Composition of Syngas}

Fig. 3 shows the syngas composition for $\mathrm{CO}, \mathrm{CO}_{2}, \mathrm{H}_{2}$ and $\mathrm{CH}_{4} . \mathrm{CO}$ composition without blending for CS and CR is lower which is about $12 \%$ and $10 \%$ respectively. The blend of $\mathrm{CS}: \mathrm{CR}$ at a ratio of $80: 20, \mathrm{CO}$ composition increases from $11.00 \%$ to $17.05 \%$. CO composition increases as the blending ratio of CS increases and synergic effect has occurred when blended biomass was used. $\mathrm{CO}_{2}$ concentration shows the highest composition of all the biomass either without blending or with blending during the co-gasification. The $\mathrm{CO}_{2}$ concentration, from the graph, showed that the highest concentration at the blending ratio of 
20:80 for CR and CS with the value of $23.81 \%$ while the lowest concentration at the blending ratio $50: 50$ of CS and $\mathrm{CR}$ with the percentage $16.25 \%$. The increase in the production of $\mathrm{CO}_{2}$ is due to the water gas shift reaction occurred during the gasification process. The $\mathrm{CH}_{4}$ concentration, $100 \%$ of $\mathrm{CR}$ without blending ratio shows the lowest concentration with the value of $4.34 \%$ and as the blending ratio increases, the concentration of $\mathrm{CH}_{4}$ also increased. The increase in blending ratio of CS gives impact to the concentration of $\mathrm{CH}_{4}$. CS alone without blending ratio has the lowest value for the production of $\mathrm{H}_{2}$. This is highly possible due to the higher moisture content contained in the CS samples. Biomass with high moisture content plays a key role in the $\mathrm{H}_{2}$ production due to the supercritical water gasification [18].

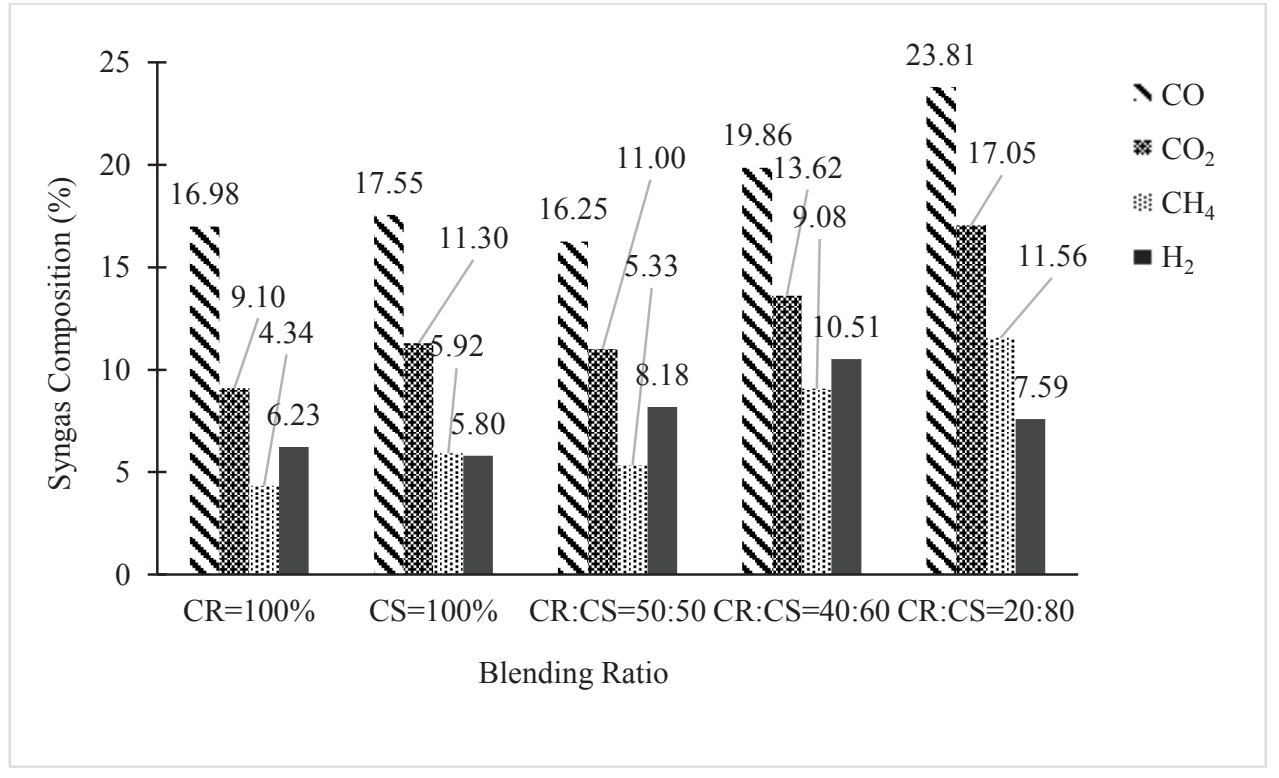

Fig. 3. Syngas composition after gasification for blending ratio of CS and CR

\section{Conclusions}

The characterization of both CS and CR are in acceptable range for biomass as a fuel for electricity generation. Most of the gas composition was affected after co-gasified. The value for $\mathrm{CO}$ composition without blending ratio is lower compared to the value after blending ratio of $\mathrm{CR}$ and $\mathrm{CS}$. The $\mathrm{CO}_{2}$ concentration increased after blending ratio since the water gas shift reaction has been increased during the increasing ratio of $\mathrm{CS}$. The increase in blending ratio of $\mathrm{CS}$ gives impact to the concentration of $\mathrm{CH}_{4}$. The blending ratio of $\mathrm{CR}$ and $\mathrm{CS}$ at 20:80 have a positive synergetic effect since the gas composition for $\mathrm{CO}, \mathrm{CH}_{4}$, and $\mathrm{H}_{2}$ were increased. It can be concluded that co-gasification results of CR and CS is practical and can be considered to complement each other.

The authors would like to give a million thanks to Mechanical Engineering Department, Universiti Teknologi PETRONAS for their support for this conference. In addition, a special thank of gratitude to YUTP for their financial support under grant YUTP 0153AA-E06 for the tuition fees provided. And also a great thanks to committee members of UTP-UMP-VIT Symposium on Energy Systems (SES) 2018. 


\section{References}

1. M. Hoogwijk, A. Faaij, R. van den Broek, G. Berndes, D. Gielen, and W. Turkenburg, Biomass and Bioenergy, 25, 119-133, (2003)

2. P. N. Sheth and B. Babu, Bioresource technology, 100, 3127-3133, (2009)

3. A. Kumar, D. D. Jones, and M. A. Hanna, Energies, 2, 556-581, (2009)

4. M. Inayat, S. A. Sulaiman, A. Kumar, and F. M. Guangul, Journal of Mechanical Engineering and Sciences, 10, pp. 2187-2199, (2016)

5. M. Inayat, S. A. Sulaiman, and J. C. Kurnia, MATEC Web Conf., 131, p. 03015, (2017)

6. M. Inayat, S. A. Sulaiman, and K. Sanaullah, 4th IET Clean Energy and Technology Conference (CEAT 2016), 1-7 (2016)

7. S. A. Sulaiman, M. Inayat, H. Basri, F. M. Guangul, and S. M. Atnaw, Journal of Mechanical Engineering and Sciences, 10, 2176-2186, 2016.

8. S. A. Sulaiman, R. Roslan, M. Inayat, and M. Yasin Naz, Journal of the Energy Institute, 91, 779785, (2018)

9. A. Friedl, E. Padouvas, H. Rotter, and K. Varmuza, Analytica Chimica Acta, 544, 191-198, (2005)

10. Y. B. Yang, C. Ryu, A. Khor, N. E. Yates, V. N. Sharifi, and J. Swithenbank, Fuel, 84, 2116-2130, (2005)

11. W. Permchart and V. I. Kouprianov, Bioresource technology, 92, 83-91, (2004)

12. P. Basu, Academic press, (2010)

13. R. García, C. Pizarro, A. G. Lavín, and J. L. Bueno, Bioresource technology, 103, 249-258, (2012)

14. R. García, C. Pizarro, A. G. Lavín, and J. L. Bueno, Fuel, 117, 1130-1138, (2014)

15. A. Demirbaş, Energy conversion and management, 42, 183-188, (2001)

16. S. Sulaiman, H. Bamufleh, S. Tamili, M. Inayat, and M. Y. Naz, 30, 465-472, (2016)

17. M. Inayat, S. A. Sulaiman, A. Abd Jamil, F. M. Guangul, and S. M. Atnaw, Proceedings of the International Conference on Global Sustainability and Chemical Engineering, 203-210 (2015)

18. T. Y. Ahmed, M. M. Ahmad, S. Yusup, A. Inayat, and Z. Khan, Renewable and Sustainable Energy Reviews, 16, 2304-2315, (2012) 